\title{
Evaluation of mast cell count in oral and cutaneous lichen planus lesions
}

\author{
Mohammad Koochak Dezfouli ${ }^{1,2}$, Fatemeh Montazer $^{3}{ }^{(}$, Atena Shiva $^{1,2}{ }^{(}$, Mahmood Moosazadeh $^{4}$, Maryam Biglari

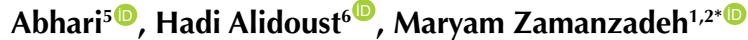 \\ ${ }^{1}$ Department of Oral and Maxillofacial Pathology, School of Dentistry, Mazandaran University of Medical Sciences, Sari, Iran \\ ${ }^{2}$ Dental Research Center, Mazandaran University of Medical Sciences, Sari, Iran \\ ${ }^{3}$ Dermatopathologist, Department of Pathology, Iran University of Medical Sciences, Tehran, Iran \\ ${ }^{4}$ Gastrointestinal Cancer Research Center, Non-communicable Diseases Institute, Mazandaran University of Medical Sciences, Sari, Iran \\ ${ }_{5}^{5}$ Preventive Medicine and Public Health Research Center, Psychosocial Health Research Institute, Community and Family Medicine \\ Department, School of Medicine, Iran University of Medical Sciences, Tehran, Iran \\ ${ }^{6}$ Dentist, Tehran, Iran
}

\section{*Correspondence to} Maryam Zamanzadeh Email:

mzamanzadeh@mazums.ac.ir, zamanzadehmaryam@gmail. com

Received 24 Jan. 2021 Accepted 24 Mar. 2021 Published online 31 July 2021

Keywords: Mast cells, Oral lichen planus, Cutaneous lichen planus

\section{Abstract}

Introduction: Lichen planus (LP) is a relatively common chronic mucocutaneous disorder diagnosed based on clinical manifestations and histopathological findings. Mast cells (MCs) are multifunctional immune cells that are involved in the pathogenesis of LP by releasing certain chemical mediators.

Objectives: The purpose of this comparative study was to estimate the number of intact (granulated), degranulated and total MCs in oral lichen planus (OLP) and cutaneous lichen planus (CLP) lesions.

Patients and Methods: The present descriptive-analytical and cross-sectional study was conducted on $125 \mathrm{LP}$ blocks, including 40 OLP samples and 85 CLP samples. The mean number of granulated, degranulated and total MCs were counted under light microscope $(\times 100$ and $\times 400)$. Data were analyzed by SPSS version 24 software using Mann-Whitney $\mathrm{U}$ and Pearson's chi-square tests.

Results: The mean total MC count was $14.92 \pm 3.90$ in OLP samples and $14.04 \pm 5.60$ in CLP samples respectively which was not statistically significant. The mean granulated MC count in CLP $(10.53 \pm 5.70)$ was higher than in OLP $(4.34 \pm 3.46)(P<0.001)$. The mean degranulated MC count in OLP $(10.57 \pm 2.99)$ was higher than in CLP $(3.51 \pm 2.72)(P<0.001)$.

Conclusion: No statistically significant difference was observed in the total MC count between OLP and CLP; however the difference in the degranulated MC count was detected between OLP and CLP. Despite the homogeneity in the total MC count, the MCs appear to play different pathological roles in OLP and CLP.

\section{Introduction}

Lichen planus (LP) is a relatively common chronic immune disease that affects the skin and mucous membranes (1). Most LP patients are middle-aged adults, whose average age at diagnosis is 55 years. This disease is rare in children and is more prevalent in women than in men (2).

The LP occurs as a chronic inflammatory autoimmune disease in skin, mucous membrane, nails, and hair follicles. The resulting lesions can range from mild inflammation to destruction of epithelial and painful wounds (3).

The classic cutaneous lichen planus (CLP) lesions are purple, pruritic and polygonal papules that most commonly involve the flexor surfaces of the extremities and cause severe pain if scratched by the patient. On closer examination, fine whitish points and

\section{Key point}

In a study on 125 Lichen planus blocks, including 40 OLP samples and 85 CLP samples, we found that the mean degranulated mast cells count in OLP was higher in CLP.

lacy lines (Wickham's striae) may be seen on the surface of the skin papules (4).

Oral lichen planus (OLP) is clinically classified into reticular, papular, plaque-like, bullous, erosive, and ulcerative types based on the appearance of its white and red areas (4).

The CLP and OLP exhibit identical histopathological alterations microscopically characterized by hyperkeratotic papules, basal cell degeneration, basement membrane thickening, and band-like lymphocytic infiltration (5).

\footnotetext{
Copyright ( $) 2022$ The Author(s); Published by Nickan Research Institute. This is an open-access article distributed under the terms of the Creative Commons Attribution License (http://creativecommons.org/licenses/by/4.0), which permits unrestricted use, distribution, and reproduction in any medium, provided the original work is properly cited.
} 
Histopathological features of the disease confirm the main role of the immune system in the development of LP. Destruction of the basal cell layer of the epithelium (hydropic degeneration) is also evident. This is accompanied by an intense, band like infiltrate of predominantly $\mathrm{T}$ lymphocytes immediately subjacent to the epithelium. This phenomenon is interpreted as a manifestation of the role of the cell-mediated immune system in the pathogenesis of LP (6).

The unknown disease-causing antigenic agent suggests autoimmune pathogenesis. On the other hand, the association of LP with autoimmune diseases, similar manifestations in graft-versus-host disease (GvHD) and loss of tolerance to autoantigen confirm the autoimmune nature of the disease (7). Self-reactive T cells are unable to distinguish between self and non-self antigens and may be important in the development of LP. However, it seems that a single peptide cannot stimulate the immune response, but several peptides do so based on the specificity of the stimulated T lymphocyte. Hence, it is very difficult to introduce a single etiologic factor for LP (8).

Mast cells (MCs) are derived from bone marrow precursors and are widely distributed in tissues. The MCs are located predominantly around arteries, nerves and sub-epithelial sites. The activated cells release a variety of mediators that act on blood vessels, smooth muscle and leukocytes (9). The MCs play an important role in innate immune responses and tissue repair by localized release of many bioactive substances. Some other roles of MCs include participating in antigen-antibody complex formation, autoimmune reactions, and $\mathrm{T}$ cell-dependent immune system responses. In other words, these cells can exert both positive and negative effects in the regulation of immune responses $(10,11)$.

\section{Objectives}

So far, studies have been conducted on the presence of inflammatory cells in LP; investigations have also compared the MCs in OLP and oral lichenoid reaction (OLR) lesions. According to the literature review, no comparison has been made so far regarding the MC count between OLP and CLP lesions. Therefore, the aim of this study was to compare the $\mathrm{MC}$ frequency, quantitative (total MC count) and qualitative [granulated (intact) and degranulated MC count] between OLP and CLP. The purpose of this comparative study was to estimate the number of intact (granulated), degranulated and total MCs in OLP and CLP lesions.

\section{Patients and Methods}

Study design

The present descriptive-analytical and cross-sectional study was conducted on paraffin embedded tissue blocks of OLP and CLP lesions. The diagnosis of LP was recorded for these samples according to clinical manifestations and histopathological findings. Four-micron cross-sections were prepared from the blocks for hematoxylin-eosin (H\&E) staining to confirm the diagnosis and enter the study. After observing H\&E-stained slides and confirming the diagnosis of paraffinated blocks, slides with sufficient connective tissue thickness and appropriate epithelial cell diameters were selected and blocks that did not meet these criteria were excluded.

Finally, 125 samples (including 85 CLP samples and 40 OLP samples) were enrolled in the study.

In the next step, $4-\mu$ cross-sections were prepared from paraffinated blocks and stained with toluidine blue (12-14). After staining, 5 densely packed cell regions of the reticular lamina propria were selected under a light microscope (Nikon, Eclipse E200, Tokyo, Japan) at magnifications of $\times 100$ and $\times 400$. The mean numbers of granulated, degranulated and total MCs were counted in these regions.

Microscopic observation and MC count were examined by two separate pathologists (dermatopathologist and oral pathologist), and the mean value would be considered if different results were obtained between the two.

\section{Data analysis}

Data were described as percentage, mean and standard deviation. The normal distribution of MC count variable was investigated by Shapiro-Wilk test. Mann-Whitney U test was performed to compare the MC count between the two groups. Gender distribution and age group were compared between the two groups by Pearson's chisquare test. Additionally, the Kruskal-Wallis test was applied to find the difference in the mean number of granulated, degranulated and total MCs based on age group. Spearman's correlation coefficient was also applied. Data were analyzed using SPSS version 24 software at a significance level of less than 0.05 .

\section{Results}

This study evaluated 125 paraffin-embedded blocks collected from 24 men (19.2\%) and 101 women (80.8\%), including 40 OLP samples (32\%) and 85 CLP samples (68\%). The mean age of research units was $43.02 \pm 13.55$ years.

Table 1 shows the frequency distribution of OLP and CLP by gender and age groups, while Pearson's chi-square test was applied to compare the two groups. As shown in this table, more cases of CLP occurred in the age group under 43 years and more cases of OLP were above 42 years of age, which is significantly different $(P=0.002)$.

The frequency of LP in women was higher than in men. OLP and CLP cases were found in $82.5 \%$ and $80 \%$ of female patients, respectively; since no statistically significant difference was observed between the two groups $(P=0.741)$.

Table 2 shows the mean granulated and degranulated MC counts in the study regions by LP type. According to the Mann-Whitney $U$ test, no statistical difference 
Table 1. Frequency distribution of oral lichen planus and cutaneous lichen planus by gender and age group

\begin{tabular}{llcc}
\hline \multirow{2}{*}{ Gender } & & CLP & OLP \\
\cline { 3 - 4 } & Male & No. $(\%)$ & No. $(\%)$ \\
\hline \multirow{3}{*}{ Age group $(y)$} & Female & $68(80)$ & $33(82.5)$ \\
& Total & $85(100)$ & $40(100)$ \\
& Pvalue & \multicolumn{2}{c}{0.741} \\
& $<33$ & $25(29.4)$ & $4(10.0)$ \\
& $33-42$ & $27(31.8)$ & $6(15.0)$ \\
& $43-52$ & $17(20.0)$ & $13(32.5)$ \\
& $>52$ & $16(18.8)$ & $17(42.5)$ \\
\hline
\end{tabular}

Abbreviations: CLP, Cutaneous lichen planus; OLP, Oral lichen planus. was observed in total MC count between OLP and CLP. However, the differences in the mean of granulated and degranulated $\mathrm{MC}$ counts were statistically significant between OLP and CLP $(P<0.001)$ and the mean granulated $\mathrm{MC}$ count was higher in CLP, while the mean degranulated MC count was greater in OLP.

Table 3 presents the mean number of granulated, degranulated and total MCs based on gender distribution. According to this table and using the Mann-Whitney $\mathrm{U}$ test, the mean number of granulated $(P=0.256)$, degranulated $(P=0.385)$ and total $(P=0.064)$ MCs was not statistically significant between men and women.

Table 4 shows the mean number of granulated, degranulated and total MCs based on age group. According to the Kruskal-Wallis test, the difference in the mean number of granulated, degranulated and total MCs based on age group is not significant between CLP and OLP.

Table 5 shows the correlation between age and number of MCs as well as between granulated and degranulated MCs based on CLP and OLP using Spearman's correlation coefficient. The results indicated no correlation between total MC count as well as granulated and degranulated MCs and age in CLP and also in OLP.

\section{Discussion}

LP is a chronic mucocutaneous disease with an unknown cause that is diagnosed according to its clinical manifestations and histopathological findings (5).

In the present study, $80 \%$ of CLP cases and $82.5 \%$ of OLP cases were observed in women. The mean age of patients was 43.02 years while the mean age was below 43 years in CLP and over 42 years in OLP. Numerous similar studies have reported LP being more common in women (15-17), although few studies have found that LP is more prevalent in men $(13,18,19)$. The age category of patients in most studies was the fifth and sixth decades of life, and the mean age in the studies of Pakfetrat et al, Ramalingam et al and Silverman et al were reported to be $41.6,43.2$ and 52 years, respectively, similar to our results $(13,20,21)$.

According to our findings, no statistically significant difference in the mean total MC count between OLP
Table 2. The mean number of granulated, degranulated and total mast cells based on LP type

\begin{tabular}{lcccc}
\hline Mast cell type & LP type & Count & Mean \pm SD & $P$ value \\
\hline \multirow{3}{*}{ Granulated } & CLP & 85 & $10.53 \pm 5.70$ & \\
& OLP & 40 & $4.34 \pm 3.46$ & $<0.001$ \\
& Total & 125 & $8.55 \pm 5.84$ & \\
Degranulated & CLP & 85 & $3.51 \pm 2.72$ & \\
& OLP & 40 & $10.57 \pm 2.99$ & $<0.001$ \\
& Total & 125 & $5.77 \pm 4.33$ & \\
Total & CLP & 85 & $14.04 \pm 5.60$ & \\
& OLP & 40 & $14.92 \pm 3.90$ & 0.184 \\
& Total & 125 & $14.32 \pm 5.11$ & \\
\hline
\end{tabular}

Abbreviations: LP, lichen planus; CLP, Cutaneous lichen planus; OLP, Oral lichen planus.

Table 3. The mean number of granulated, degranulated and total mast cells based on gender distribution

\begin{tabular}{lllll}
\hline Mast cell type & Gender & Count & Mean \pm SD & $P$ value \\
\hline \multirow{3}{*}{ Granulated } & Male & 24 & $7.75 \pm 6.56$ & \\
& Female & 101 & $8.74 \pm 5.68$ & 0.256 \\
& Total & 125 & $8.55 \pm 5.84$ & \\
\multirow{5}{*}{ Degranulated } & Male & 24 & $5.23 \pm 4.29$ & \\
& Female & 101 & $5.90 \pm 4.35$ & 0.385 \\
& Total & 125 & $5.77 \pm 4.33$ & \\
Total & Male & 24 & $12.99 \pm 5.89$ & \\
& Female & 101 & $14.64 \pm 4.89$ & 0.064 \\
& Total & 125 & $14.32 \pm 5.11$ & \\
\hline
\end{tabular}

and CLP was detected, however the differences in the mean number of granulated and degranulated MCs were statistically significant between OLP and CLP. Additionally, the mean granulated MC count was higher in CLP and the mean degranulated MC count was greater in OLP. The role of MCs has been demonstrated in the pathology of OLP and CLP lesions $(22,23)$. Mucosal MCs are linked to nerve fibers and vessels, and chronic stimulation of these nerves and secretion of neuropeptides induces MC degranulation. The MC degranulation is induced by $\operatorname{IgE}$ receptor or interaction with a variety of agonists that act directly on the cell surface. Both T cell-derived cytokines and MC-T cell adhesion may cause MC activation and degranulation (4).

Various studies compared MC counts in OLP and OLR, which compared in this study.

We found that the mean MC count in OLP was 14.92 \pm 3.9 , in line with the results of the study by Ramalingam et al $(14.98 \pm 5.16)$. In their study, the mean MC count in OLR and in normal mucosa was less than this value, 7.96 and 2.02, respectively (13).

Reddy et al (12) observed an increase in MC count in LP and OLR compared to normal mucosa. Consistent results reported in the studies of Sharma et al, Zhao et al and Juneja et al emphasize the important role of MCs in the pathogenesis of these lesions (24-26). In the study of Reddy et al (12), the mean numbers of total MCs and 
Table 4. The mean number of granulated, degranulated and total mast cells based on age group

\begin{tabular}{|c|c|c|c|c|c|}
\hline $\begin{array}{l}\text { Lichen } \\
\text { planus type }\end{array}$ & $\begin{array}{l}\text { Mast cell } \\
\text { type }\end{array}$ & $\begin{array}{l}\text { Age } \\
\text { group }\end{array}$ & Count & Mean \pm SD & $P$ value \\
\hline \multirow{15}{*}{$\begin{array}{l}\text { Cutaneous } \\
\text { lichen } \\
\text { planus }\end{array}$} & \multirow{5}{*}{ Granulated } & $<33$ & 25 & $9.10 \pm 5.08$ & \multirow{5}{*}{0.229} \\
\hline & & $33-42$ & 27 & $12.39 \pm 6.30$ & \\
\hline & & $43-52$ & 17 & $10.01 \pm 6.02$ & \\
\hline & & $>52$ & 16 & $10.16 \pm 4.81$ & \\
\hline & & Total & 85 & $10.53 \pm 5.70$ & \\
\hline & \multirow{5}{*}{ Degranulated } & $<33$ & 25 & $3.30 \pm 2.50$ & \multirow{5}{*}{0.810} \\
\hline & & $33-42$ & 27 & $3.62 \pm 3.18$ & \\
\hline & & $43-52$ & 17 & $3.43 \pm 2.83$ & \\
\hline & & $>52$ & 16 & $3.75 \pm 2.26$ & \\
\hline & & Total & 85 & $3.51 \pm 2.72$ & \\
\hline & \multirow{5}{*}{ Total } & $<33$ & 25 & $12.40 \pm 4.30$ & \multirow{5}{*}{0.117} \\
\hline & & $33-42$ & 27 & $16.01 \pm 6.10$ & \\
\hline & & $43-52$ & 17 & $13.45 \pm 6.52$ & \\
\hline & & $>52$ & 16 & $13.91 \pm 4.91$ & \\
\hline & & Total & 85 & $14.04 \pm 5.60$ & \\
\hline \multirow{15}{*}{$\begin{array}{l}\text { Oral lichen } \\
\text { planus }\end{array}$} & \multirow{5}{*}{ Granulated } & $<33$ & 25 & $4.12 \pm 1.74$ & \multirow{5}{*}{0.836} \\
\hline & & $33-42$ & 27 & $3.96 \pm 2.46$ & \\
\hline & & $43-52$ & 17 & $4.45 \pm 3.21$ & \\
\hline & & $>52$ & 16 & $4.45 \pm 4.35$ & \\
\hline & & Total & 85 & $4.34 \pm 3.46$ & \\
\hline & \multirow{5}{*}{ Degranulated } & $<33$ & 25 & $11.77 \pm 2.32$ & \multirow{5}{*}{0.701} \\
\hline & & $33-42$ & 27 & $9.55 \pm 4.19$ & \\
\hline & & $43-52$ & 17 & $10.22 \pm 3.01$ & \\
\hline & & $>52$ & 16 & $10.92 \pm 2.75$ & \\
\hline & & Total & 85 & $10.57 \pm 2.99$ & \\
\hline & \multirow{5}{*}{ Total } & $<33$ & 25 & $15.90 \pm 3.91$ & \multirow{5}{*}{0.859} \\
\hline & & $33-42$ & 27 & $13.51 \pm 5.32$ & \\
\hline & & $43-52$ & 17 & $14.67 \pm 3.79$ & \\
\hline & & $>52$ & 16 & $15.38 \pm 3.64$ & \\
\hline & & Total & 85 & $14.92 \pm 3.90$ & \\
\hline
\end{tabular}

degranulated MCs in OLP were lower than our study, $12.56 \pm 3.30$ and $6.69 \pm 2.97$, respectively, nevertheless the mean granulated MC count $(5.86 \pm 3.02)$ was higher than our study. In this study, the granulated MC count in OLP was significantly higher than in OLR, while the degranulated MC count was greater in OLR. The study suggested that an increase in granulated MC count in oral lichenoid mucositis may indicate that MC degranulation is induced by chemical substances or drugs associated with the disease. It therefore reinforces the hypothesis that oral lichenoid mucositis mimics a hypersensitivity reaction in which MC degranulation plays a major role (12).

Pereira et al (27) examined the number of MCs in OLP and inflamed gingival mucosa $(\operatorname{Ig} M)$, and reported that the mean numbers of granulated, degranulated and total MCs in OLP were lower than our results $(0.68 \pm 0.44,8.04$ \pm 2.49 and $8.72 \pm 2.53$, respectively). In this study, the density of MCs and degranulated MCs in LP was higher than in control group. Moreover, the basement membrane thickness was lower in LP and a clear fragmentation was observed in the basement membrane of LP compared to $\operatorname{Ig}$.

The total MC count in the studies of Zhao et al (25), Juneja et al (26) and Balci \& Ercin (28) was not significantly different between OLP and OLR lesions. Furthermore in the studies of Jose et al (29) and Reddy et al (12), the number of degranulated MCs stained with toluidine blue in OLR was significantly higher than in OLP. The studies suggested that these findings may be considered as a diagnostic marker in the differential diagnosis of OLP and OLR. In contrast, Juneja et al (26) observed that the mean total MC count and the mean degranulated MC count in OLP were higher than in OLR. Analyzing the results of the present study and increasing the degranulated MC count raised the following questions. Can a different role be imagined for MCs in OLP? Does the underlying difference between mucus and skin cause this change in function? Is an increase in degranulated MC count in OLP related to an increase in malignancy compared to CLP? Can it be concluded that MC stabilizers may show better performance in the mucosa? Further research in this area may answer these questions, and it is also suggested to conduct studies with larger sample size.

\section{Conclusion}

There was no statistically significant difference in the total MC count between OLP and CLP, however the difference in the degranulated MC count was significant between OLP and CLP. Despite the homogeneity in the total MC count, the MCs appear to play different pathological roles in OLP and CLP.

\section{Limitations of the study}

The limitation of the study was small size of oral samples compared with cutaneous blocks.

Authors' contribution

$M Z, M K D, F M$ and AS were the principal investigators of the study. $M Z, M K D, F M, A S$ and $H A$ were included in preparing the concept

Table 5. Correlation between age and number of MCs as well as between granulated and degranulated MCs based on cutaneous lichen planus and oral lichen planus

\begin{tabular}{|c|c|c|c|c|}
\hline Lichen planus type & & Granulated mast cells & Degranulated mast cells & Total mast cells \\
\hline \multirow{3}{*}{ Cutaneous lichen planus } & Correlation Coefficient & 0.10 & 0.05 & 0.12 \\
\hline & Sig. (2-tailed) & 0.33 & 0.59 & 0.24 \\
\hline & Count & 85 & 85 & 85 \\
\hline \multirow{3}{*}{ Oral lichen planus } & Correlation Coefficient & -0.11 & 0.11 & 0.05 \\
\hline & Sig. (2-tailed) & 0.47 & 0.48 & 0.72 \\
\hline & Count & 40 & 40 & 40 \\
\hline
\end{tabular}


and design. MM managed the analyses of the study. MZ and MBA revisited the manuscript and critically evaluated the intellectual contents. All authors participated in preparing the final draft of the manuscript, revised the manuscript and critically evaluated the intellectual contents. All authors have read and approved the content of the manuscript and confirmed the accuracy or integrity of any part of the work.

Conflicts of interest

The authors declare that they have no competing interests.

\section{Ethical issues}

The research followed the tenets of the Declaration of Helsinki. The Ethics Committee of Mazandaran University of Medical Sciences approved this study (IR.MAZUMS.REC.1398.482). Informed consent was obtained from participants. This study was extracted from DDs thesis of Hadi Alidoust at this university (Thesis\#2062). Moreover, Ethical issues (including plagiarism, data fabrication, double publication) have been completely observed by the authors.

\section{Funding/Support}

The authors of this article express their gratitude to the officials of Mazandaran University of Medical Sciences, for approving and funding this project (Grant\# 3334).

\section{References}

1. Neville BW, Damm DD, Allen CM, Chi AC. Oral and maxillofacial pathology. Elsevier Health Sciences; 2015.

2. Varghese SS, George GB, Sarojini SB, Vinod S, Mathew P, Mathew DG, et al. Epidemiology of Oral Lichen Planus in a Cohort of South Indian Population: A Retrospective Study. J Cancer Prev. 2016;21:55-9. doi: 10.15430/jcp.2016.21.1.55.

3. Scully C, Carrozzo M. Oral mucosal disease: Lichen planus. Br J Oral Maxillofac Surg. 2008;46:15-21. doi: 10.1016/j. bjoms.2007.07.199.

4. Gorouhi F, Davari P, Fazel N. Cutaneous and mucosal lichen planus: a comprehensive review of clinical subtypes, risk factors, diagnosis, and prognosis. ScientificWorldjournal. 2014;2014:742826. doi: 10.1155/2014/742826.

5. Ellis FA. Histopathology of lichen planus based on analysis of one hundred biopsy specimens. J Invest Dermatol. 1967;48:143-8. doi: 10.1038/jid.1967.23.

6. Liu Y, Liu G, Liu Q, Tan J, Hu X, Wang J, et al. The cellular character of liquefaction degeneration in oral lichen planus and the role of interferon gamma. J Oral Pathol Med. 2017;46:1015-22. doi: 10.1111/jop.12595.

7. McParland H. Oral Lichenoid and Lichen Planus-like Lesions. Prim Dent J. 2016;5:34-9. doi: 10.1177/205016841600500103.

8. Kurago ZB. Etiology and pathogenesis of oral lichen planus: an overview. Oral Surg Oral Med Oral Pathol Oral Radiol. 2016;122:72-80. doi: 10.1016/j.oooo.2016.03.011.

9. Kumar V, Abbas AK, Aster JC. Robbins basic pathology e-book. Elsevier Health Sciences; 2017.

10. Hallgren J, Estrada S, Karlson U, Alving K, Pejler G. Heparin antagonists are potent inhibitors of mast cell tryptase. Biochemistry. 2001;40:7342-9. doi: 10.1021/bi001988c.

11. Marshall JS. Mast-cell responses to pathogens. Nat Rev Immunol. 2004;4:787-99. doi: 10.1038/nri1460.

12. Reddy DS, Sivapathasundharam B, Saraswathi TR, SriRam G. Evaluation of mast cells, eosinophils, blood capillaries in oral lichen planus and oral lichenoid mucositis. Indian J Dent Res. 2012;23:695-6. doi: 10.4103/0970-9290.107422.

13. Ramalingam S, Malathi N, Thamizhchelvan H, Sangeetha N,
Rajan ST. Role of Mast Cells in Oral Lichen Planus and Oral Lichenoid Reactions. Autoimmune Dis. 2018;2018:7936564. doi: 10.1155/2018/7936564.

14. Bancroft JD, Cook HC. Manual of Histological Techniques and their Diagnostic Application. Churchill Livingstone; 1994.

15. Garg VK, Nangia A, Logani K, Sharma RC. Lichen Planus-a Clinico-histopathological. Indian J Dermatol Venereol Leprol. 2000;66:193-5.

16. Ingafou M, Leao JC, Porter SR, Scully C. Oral lichen planus: a retrospective study of 690 British patients. Oral Dis. 2006;12:463-8. doi: 10.1111/j.1601-0825.2005.01221.x.

17. Fernández-González F, Vázquez-Álvarez R, Reboiras-López D, Gándara-Vila P, García-García A, Gándara-Rey JM. Histopathological findings in oral lichen planus and their correlation with the clinical manifestations. Med Oral Patol Oral Cir Bucal. 2011;16:e641-6.

18. Dixit D VS, Giriyan SS. A clinico-pathological study of lichenoid tissue reactions/interface dermatitis. Int J Res Med Sci. 2019;7(4):1002.

19. Chauhan R, Srinath M, Ali NM, Bhat RM, Sukumar D. Clinicopathological study of lichenoid reactions: a retrospective analysis. Journal of Evolution of Medical and Dental Sciences. 2015;4:5551-64

20. Oliveira Alves MG, Almeida JD, Balducci I, Guimarães Cabral LA. Oral lichen planus: A retrospective study of 110 Brazilian patients. BMC Res Notes. 2010;3:157. doi: 10.1186/17560500-3-157.

21. Silverman S, Jr., Gorsky M, Lozada-Nur F, Giannotti K. A prospective study of findings and management in 214 patients with oral lichen planus. Oral Surg Oral Med Oral Pathol. 1991;72:665-70. doi: 10.1016/0030-4220(91)90007-y.

22. Sugerman PB, Savage NW, Walsh LJ, Zhao ZZ, Zhou XJ, Khan A et al. The pathogenesis of oral lichen planus. Crit Rev Oral Biol Med. 2002;13:350-65. doi: 10.1177/154411130201300405.

23. Lodi G, Scully C, Carrozzo M, Griffiths M, Sugerman PB, Thongprasom K. Current controversies in oral lichen planus: report of an international consensus meeting. Part 1. Viral infections and etiopathogenesis. Oral Surg Oral Med Oral Pathol Oral Radiol Endod. 2005;100:40-51. doi: 10.1016/j. tripleo.2004.06.077.

24. Sharma R, Sircar K, Singh S, Rastogi V. Role of mast cells in pathogenesis of oral lichen planus. J Oral Maxillofac Pathol. 2011;15:267-71. doi: 10.4103/0973-029x.86674.

25. Zhao ZZ, Sugerman PB, Zhou XJ, Walsh LJ, Savage NW. Mast cell degranulation and the role of T cell RANTES in oral lichen planus. Oral Dis. 2001;7:246-51.

26. Juneja M, Mahajan S, Rao NN, George T, Boaz K. Histochemical analysis of pathological alterations in oral lichen planus and oral lichenoid lesions. J Oral Sci. 2006;48:185-93. doi: 10.2334/josnusd.48.185.

27. Pereira T, Aswathy J, Shetty S, Tamgadge A, Tamgadge S, Gotmare S. Quantitative and Qualitative Analysis of Mast Cells in Oral Lichen Planus and Its Effect on Basement Membrane Using Special Stains. Indian Dermatol Online J. 2019;10:4316. doi: 10.4103/idoj.IDOJ_147_18.

28. Balci M, Ercin ME. Evaluation of mast cell distribution in oral lichen planus and lichenoid lesions by immunohistochemical and histochemical analysis. Am J Immunol. 2016;12:99-106. doi: 10.3844/AJISP.2016.99.106

29. Jose M, Raghu AR, Rao NN. Evaluation of mast cells in oral lichen planus and oral lichenoid reaction. Indian J Dent Res. 2001; 12:175-9. 